AGRICA: Journal of Sustainable Dryland Agriculture, 13 (2): 179-198 (2020)

ISSN-Online: 2715-4955; ISSN-Cetak: 2715-6613

DOI: 10.37478 /agr.v13i2.389

\title{
ANALISIS PENDAPATAN USAHA TANI KAKAO DI KABUPATEN ENDE (Kajian pada Desa Kedebodu dan Rewarangga)
}

\author{
Imaculata Fatima \\ Program Studi Agroteknologi Fakultas Pertanian Universitas Flores \\ Jl. Sam Ratulangi XX-Paupire, Kabupaten Ende, Nusa Tenggara Timur \\ e-mail: imapampe@gmail.com
}

\begin{abstract}
Analysis of Cocoa Farming Income in Ende District (Study at Kedebodu and Rewarangga Villages). Based on these considerations, this study aims to determine the level of cocoa farming income and the factors that influence farmers' income, and analyze the feasibility and usefulness of a cocoa farming fund. The method used in this research is descriptive method. The research location was determined by purposive sampling, based on the consideration that the area is a cocoa-producing region in Ende Regency. Sampling is the Ende Selatan District of Kedebodu and Rewarangga Villages. The population is all cocoa farmers, with a sample of 20 respondents. Data was collected by interview, questionnaire, observation, and documentation techniques. The feasibility analysis is done by $\mathrm{B} / \mathrm{C}$ ratio analysis. In addition to the analysis also conducted an analysis of income and receipts with the formula TC and TR. The results showed a $\mathrm{B} / \mathrm{C}$ ratio of $5.24 \%$ which meant that the cocoa business was profitable and feasible to be developed. Total income from cocoa and non-cocoa is Rp 315,732,000. and from cocoa alone. Rp 91,532,000, - and total revenue of Rp. 73,897,000, and noncocoa Rp. 29,933,000. While the total cost of cocoa is IDR 17,635,000 and non-cocoa IDR 194,267,000. Factors influencing the cocoa business in Ende District include, level of education, gender participation, labor age, age of old cocoa plants, and not yet applying profitable technology. It is advisable for farmers to intensify cocoa farming by implementing P3S, and post-harvest processing, farming young people groups and building networks of cooperation with all stakeholders.
\end{abstract}

Keywords: Cocoa, Farming, Feasibility, Income

\section{PENDAHULUAN}

Indonesia merupakan negara yang kaya akan potensi sumber daya alam sehingga banyak dikembangkan usaha diberbagai sektor khususnya bidang pertanian seperti tanaman pangan, perkebunan, kehutanan, perikanan, dan peternakan yang bertujuan untuk meningkatkan produksi pertanian dan pendapatan petani. Sektor perkebunan yang diusahakan masyarakat salah satu diantaranya adalah tanaman kakao. Kakao masih tergolong komoditi yang sangat penting di Indonesia. Kondisi tersebut ditunjukkan dengan besarnya kebutuhan kakao dalam negeri yang 
mencapai 800.000 ton/tahun sementara produksi kakao yang dihasilkan di Indonesia hanya 315.000 ton/tahun, dan sisanya diimpor (Kementrian Perindustrian, 2015).

Berdasarkan kondisi tersebut maka kakao atau cokelat (Theobroma Cacao) dijadikan sebagai komoditas perkebunan unggulan yang banyak dikembangkan di Indonesi. Melalui Keputusan Pertanian dan Perkebunan (Kepmentan) No. 46/Kpts/PD.3000/2015 Kabupaten Ende, Nusa Tenggara Timur (NTT) telah ditetapkan sebagai salah satu kawasan perkebunan kakao. Menindaklanjuti Kepmen tersebut maka Kabupaten Ende dalam RPJM 20142019 menetapkan kakao sebagai komoditas andalan utama dalam pembangunan.

Pertimbangan kakao dijadikan sebagai produk unggulan adalah : (1) Produksi kakao merupakan yang tertinggi dari produk lain yakni 8,334 ton pada tahun 2015 menjadi 161.160 ton pada tahun 2017; (2) Luasan Lahan pada komoditas kakao meningkat sebesar 4\% yaitu dari 14.631 ha tahun 2015 menjadi 28.724 ha tahun 2017; (3) Jumlah tenaga kerja yang bekerja pada komoditas kakao terjadi peningkatan dari 10.878 kk pada tahun 2015 menjadi 11.388 kk tahun 2017 (Dishutbun Kabupaten, 2018). Penelitian Jaweng (2015) menyatakan kakao merupakan penyumbang terbesar dalam PDRB Kabupaten Ende dibandingkan dengan komoditas-komoditas lainnya. Besarnya pangsa dalam PDRB, komoditas Kakao sebanyak 0.29\%, PDRB di sektor pertanian juga menyumbang persentase tertinggi dibandingkan komoditas lain, yakni sebesar $0.88 \%$, dan dalam PDRB perkebunan, berkontribusi sebanyak 3.44\%. Usaha kakao Kabupaten Ende, dikembangkan pada hampir semua kecamatan, termasuk kecamatan Ende Timur pada Desa Kedebodu dan Rewarangga. Kedua Desa ini merupakan batas terluar kota Ende tepatnya berada pada kilometer delapan kota Ende dengan luas wilayah 762,1 ha dan memiliki jumlah penduduk 671 jiwa.

Ditinjau dari kondisi geografi, kedua desa ini berpotensi untuk dikembangkan tanaman kakao. Berdasarkan hasil survey dan wawancara dengan petani, diketahui bahwa rata-rata petani memiliki areal pertanaman kakao seluas 3 ha/orang dengan produktivitas sebanyak $112 \mathrm{~kg} / \mathrm{ha}$ (biji kakao kering). 
Fatima: Analisis pendapatan usaha tani kakao

Produksi tersebut masih sangat jauh dari produktivitas kakao yang seharusnya yakni berkisar 1.150-2.000 kg/ha (Siswanto, 2012; Murtiningrum, 2016).

Pendapatan dapat dibedakan menjadi dua yaitu pendapatan usahatani dan pendapatan rumah tangga (Gustiyana, 2003). Pendapatan merupakan pengurangan dari penerimaan dengan biaya total. Pendapatan rumah tangga yaitu pendapatan yang diperoleh dari kegiatan usaha tani ditambah dengan pendapatan yang berasal dari kegiatan diluar usaha tani. Pendapatan usaha tani adalah selisih antara pendapatan kotor (output) dan biaya produksi (input) yang dihitung dalam per bulan, per tahun, per musim tanam. Pendapatan luar usaha tani adalah pendapatan yang diperoleh sebagai akibat melakukan kegiatan di luar usaha tani seperti berdagang, mengojek, tukang, beternak, dan memelihara ikan.

Berbagai masalah petani dalam peningkatan pendapatan, dan kesejahteraan antara lain pengetahuan petani yang relatif rendah, keterbatasan modal, lahan garapan yang sempit, dan kurangnya keterampilan petani dan berpengaruh pada penerimaan petani. Menurut Soeratno dan Linconl (2005) ukuran pendapatan yang digunakan untuk tingkat kesejahteraan keluarga adalah pendapatan rumah tangga yang diperoleh dari bekerja. Menurut Hermanto (2015) pendapatan petani dialokasikan untuk kegiatan produktif (yaitu untuk membiayai kegiatan usaha taninya), kegiatan konsumtif (yaitu untuk pangan, papan, kesehatan, pendidikan, rekreasi, dan pajak), pemeliharaan investasi, dan investasi serta tabungan.

Ende Timur merupakan salah satu kecamatan yang mengembangkan kakao terutama pada Desa Kedebodu dan Rewarangga. Kakao merupakan komoditi unggulan yang pengembangannya perlu dioptimalkan secara berkelanjutan sebagai salah satu sumber pendapatan rumah tangga petani. Di sisi lain, kurangnya kelembagaan pemasaran usaha kakao juga menjadi kendala bagi petani dalam memasarkan produknya, karena berpengaruh secara langsung terhadap tingkat pendapatan. Walaupun demikian, para petani tetap mengusahakan tanaman kakao secara berkelanjutan sebagai salah satu sumber pendapatan rumah tangganya. Namun usahanya belum didasarkan pada analisis usaha tani sehingga pendapatan petani belum diketahui dengan pasti. Oleh 
karena itu, penelitian ini dilakukan untuk mengkaji usaha tani kakao dan faktorfaktor yang mempengaruhi tingkat pendapatan petani kakao, serta kelayakan untuk dikembangkan.

\section{BAHAN DAN METODE}

\section{Tempat dan Waktu}

Lokasi penelitian dilakukan di Desa Kedebodu dan Rewarangga Kecamatan Ende Timur Kabupaten Ende dengan komoditas utama adalah kakao. Lokasi penelitian ditentukan secara sengaja (purposive sampling), dengan pertimbangan bahwa daerah tersebut merupakan wilayah penghasil kakao. Penelitian ini berlangsung selama tujuh bulan.

\section{Pelaksanaan Penelitian}

Populasi yang ditetapkan adalah seluruh petani kakao berjumlah 198 kepala keluarga, dengan sampelnya 10\% dari populasi yakni 20 orang responden. Menurut Gay (1992). Pengumpulan data dilakukan dengan teknik wawancara kepada para petani, dan pengisian angket yang dibantu oleh beberapa mahasiswa untuk mendampingi para petani karena ada tidak berpendidikan, observasi dilakukan di lokasi atau kebun petani bersama mahasiswa untuk menghitung jumlah tanaman kakao yang produktif, dan rusak, serta pengamatan tentang ekologi kebun kakao, dan dokumentasi sebagai pendukung.

Data yang digunakan adalah data primer yang diperoleh dari petani kakao sebagai responden melalui teknik wawancara dengan menggunakan kuisioner, dan data sekunder diperoleh dari literatur dan lembaga/instansi terkait.

\section{Analisis Data}

Analisis data dilakukan untuk mengetahui tingkat pendapatan dari usahatani kakao diasumsikan lebih besar dari biaya yang dikeluarkan per musim panen. Selanjutnya data yang diperoleh dari kuisioner ditabulasi dan dianalisis secara deskriptif. Tingkat pendapatan petani kakao dan variabelvariabel yang berpengaruh terhadap pendapatan petani pertahun dilakukan analisis pendapatan usahatani kakao rakyat dapat dihitung dengan mengurangkan pendapatan dengan seluruh biaya yang benar-benar dikeluarkan (Soekartawi, 2005).

$$
\text { Rumusan tentang Total Biaya }
$$

(TC), Penerimaan Total (TR), Pendapatan (NR) dan Penerimaan Total (TR) adalah sebagai berikut:

$\mathrm{TC}=\mathrm{TFC}+\mathrm{TVC}$

$\mathrm{TR}=\mathrm{Q} \times \mathrm{P}$

$\mathrm{NR}=\mathrm{TR}-\mathrm{TC}$ 
$\mathrm{TR}=\mathrm{Q} \times \mathrm{PTC}=\mathrm{TFC}+\mathrm{TVC}$

Ketet

TC = Total biaya (Rp),

TVC = Total Biaya Variabel $(\mathrm{Rp})$,

TFC = Total Biaya Tetap (Rp),

TR = Penerimaan total $(\mathrm{Rp})$,

Q = Jumlah produksi $(\mathrm{kg})$,

$\mathrm{P}=$ Harga $(\mathrm{Rp})$.

Selanjutnya untuk mengetahui keuntungan, digunakan rumus $\mathrm{B} / \mathrm{C}$ ratio seperti berikut ini:

$\mathrm{B} / \mathrm{C}$ Ratio = Jumlah Pendapatan (B) : Total Biaya Produksi (TC)

Keterangan: Kriteria pengambilan keputusan adalah sebagai berikut.

a) Jika $\mathrm{B} / \mathrm{C}$ ratio $>1$, maka usaha tani yang dilakukan menguntungkan, karena penerimaan lebihbesar dari biaya total.

b) JikaB/C $<1$, maka usaha tani yang dilakukan tidak menguntungkan, karena penerimaan lebih kecil daripada biaya total.

c) Jika $\mathrm{B} / \mathrm{C}=1$, maka usaha tani yang dilakukan tidak menguntungkan dan tidak merugikan atau pulang pokok (Soekartawi, 2005)

\section{HASIL DAN PEMBAHASAN}

\section{Umur dan Jenis Kelamin Petani}

Berdasarkan umur, rata-rata berumur 50 tahun. Umur termuda 23 tahun dan tertua 80 tahun. Umur petani kurang produktif sebesar $31 \%$, dan umur produktif $69 \%$, serta peran kaum muda hanya $8 \%$ dan partisipasinya diklasifikasikan rendah. Kaum muda lebih banyak bekerja pada non-pertanian, sehingga berdampak negatif pada keberlanjutan usaha kakao sebagai salah satu sumber pendapatan. Sebaliknya banyaknya petani kakao usia produktif memungkinkan penyerapan informasi dan inovasi lebih tinggi. Wibowo (2006) menyatakan bahwa usia produktif manusia berada pada kisaran umur 14-55 tahun. Berdasarkan jenis kelamin partisipasi perempuan sangat tinggi yakni 13 orang yang juga berperan menjual kakao di Pasar dan tujuh orang pria. Oleh karena itu, perlu membentuk lembaga usaha tani perempuan untuk menunjang kelangsungan ekonomi rumah tangganya. Sedangkan keputusan lain untuk persiapan lahan, pemeliharaan, panen, dan pasca panen dilakukan atas kesepakatan bersama anggota keluarga. Sejalan dengan pendapat Widodo (2012), bahwa istri perlu berperan mencari tambahan penghasilan untuk memenuhi kebutuhan keluarga, sehingga mereka tidak hanya tinggal diam di rumah, namun mereka juga harus ikut terlibat dalam kegiatan mencari nafkah dalam bentuk usaha 
kelompok bersama. Hariadi (2011) juga mengemukakan wanita melakukan peran kompleks, karena tidak hanya mengurus rumah tangga tetapi juga aktif dalam peran ekonomi dan sosialnya.

\section{Pendidikan Petani}

Pendidikan petani kakao umumnya Sekolah Dasar yakni 15 orang, dan lima orang tidak sekolah. Kondisi ini menjadi kendala dalam menerima adopsi teknologi, seperti kurang memahami manfaat P3S dan membiarkan buah kakao busuk di pohon, upaya pengendalian hama dan pemupukan masih kurang, serta kurang memahami manfaat kakao difermentasi, yang berdampak pada rendahnya kualitas, kuantitas, dan harga kakao dipasaran. Hasil penelitian Wahyuni (2019) menyatakan kegiatan perbaikan teknik budidaya menjadi penentu untuk mendapatkan kuantitas dan kualitas yang baik sesuai permintaan pasar, dan menjadi lebih mudah untuk melakukan inovasi dalam pengembangan produk, serta kegiatan pemasaran. Tingkat pendidikan juga mempengaruhi pola pikir dan memungkinkan untuk mengembangkan, serta meningkatkan hasil pertanian kearah yang lebih baik. Kusnadi (2005) juga menyatakan bahwa pendidikan dapat mempertahankan stabilitas, kontinuitas dan mendorong untuk masa depan yang lebih baik.

\section{Jumlah Anggota Keluarga yang Ditanggung}

Usaha kakao membutuhkan tenaga kerja yang cukup banyak. Dari $20 \mathrm{KK}$ tenaga kerja yang dilibatkan adalah sebanyak 76 orang, dan beberapa sewa tenaga dari luar yang sifatnya insidentil. Rata-rata tanggungan per keluarga, enam orang. Jumlah anggota keluarga juga berpengaruh terhadap pendapatan yakni bertambahnya jumlah tanggungan akan mengurangi pendapatan keluarga. Widodo (2012) mengatakan bahwa jumlah anak yang meningkat, maka beban tanggungan dari keluarga akan meningkat. Amini (2013) mengemukakan makin banyak waktu untuk mengurus anak sehingga waktu bekerja di lahan garapan maupun berdagang semakin berkurang akibatnya pendapatan akan menurun.

\section{Partisipasi dalam Organisasi}

Ekonomi di Desa

Organisasi ekonomi yang dimaksud adalah Kelompok Tani, Gapoktan, Bumdes, Koperasi, dan Credit Union. Beberapa petani telah bergabung dalam kelompok tani Wonga Mengi, Worowae Sare, Karya Mandiri, dan Beringin Indah dengan lama bergabung 
rata-rata empat tahun. Petani merasakan manfaatnya antara lain untuk tujuan gotong royong dalam bekerja, sharing pengalaman diantara petani tentang manfaat ekonomi usaha kakao. Manfaat lainnya adalah pembelian peralatan, transportasi, dan biaya lainnya dilakukan secara kolektif. Hal ini berdampak pada peningkatan pendapatan pada setiap petani yakni Rp 25.210.000,-. Ikbal (2014) mengatakan bahwa tujuan dibentuknya kelompok tani adalah untuk meningkatkan dan mengembangkan kemampuan petani dan keluarganya sebagai subjek pendekatan kelompok, agar lebih berperan dalam pembangunan.

Tujuan organisasi kelompok tani adalah membantu para petani untuk mengorganisasikan dirinya dalam mengakses teknologi, permodalan, pasar dan sumberdaya lainnya agar meningkatkan produktivitas, efisiensi usaha, pendapatan dan kesejahteraannya, serta meningkatkan kesadaran dalam pelestarian fungsi lingkungan hidup (Balai Penelitian Tanaman Pangan, 2011).

\section{Kepemilikan Lahan}

Setiap petani memiliki lahan ratarata tiga hektar dengan total luasan tanaman kakao sebesar 32\% dan kakao belum menjadi prioritas. Selain kakao, juga kemiri, pisang, cengkeh, kelapa, pinang, kopi, dan sirih. Status kepemilikan lahan semuanya milik sendiri namun sebanyak $85 \%$ belum memiliki legalitas kepemilikan atau belum bersertifikat. Kondisi ini sangat rawan untuk digugat oleh pihak yang tidak bertanggung. Terkait dengan itu Hadiana (2013) menyatakan bahwa penguasaan lahan meliputi hubungan antara individu (perseorangan), badan hukum ataupun masyarakat sebagai suatu kolektivitas atau masyarakat hukum dengan lahan/tanah yang mengakibatkan hak-hak dan kewajiban terhadap lahan/tanah. Lahan yang luas berdampak pada peningkatan hasil, dan pendapatan, serta kesejahteraan masyarakat. Selanjutnya penggunaan lahan produktif selain kakao terlihat pada Tabel 1 dan 2 berikut. 
Tabel 1. Jumlah Petani Kakao Berdasarkan Jenis Produksi Rumah Tangga

\begin{tabular}{|c|c|c|c|c|c|c|c|c|c|c|}
\hline No. & Tan.Pangan & $\%$ & Tan.Dagang & $\%$ & Sayuran & $\%$ & Ternak & $\%$ & Tan.Kayu & $\%$ \\
\hline 1 & Padi & 17 & Kemiri & 39 & Daun ubi & 54 & Babi & 55 & \multirow{4}{*}{$\begin{array}{l}\text { Jati \& } \\
\text { mahoni }\end{array}$} & \multirow[t]{4}{*}{72} \\
\hline 2 & Jagng & 15 & Kelapa & 1 & kangkg & 36 & Sapi & 35 & & \\
\hline 3 & Kacng & 73 & Cengkeh & 60 & Selada & 10 & Kambng & 5 & & \\
\hline 4 & Ubi kayu & 9 & & & & & Ayam & 5 & & \\
\hline & & 100 & & 10( & & 100 & & 100 & & 72 \\
\hline
\end{tabular}

Sumber: data primer (diolah), 2017

Tabel 1 menunjukkan variasi pemanfaatan lahan yang berdampak positip yakni manfaat ekonomi, sosial, dan pelestarian lingkungan. Dalam pembuatan kebun agroforestri, pemanfaatan jenis dengan siklus hidup yang berbeda menjamin persediaan bahan organik pada ekosistem yang berdampak pada kesuburan tanah sehingga biaya pupuk dapat ditekan, dan variasi tanaman memperkaya keanekaragaman hayati, memaksimalkan pendapatan secara berkelanjutan, dan meminimalkan resiko ekonomi. Sejalan dengan itu, Terhorst (2014) mengemukakan bahwa pohon penghasil buah dan kayu memberikan naungan sehingga kakao tumbuh sehat dan jauh lebih resisten terhadap hama penyakit dibandingkan kakao yang terus menerus terpapar sinar matahari langsung. Menurut Kotto (1997) agroforest kakao mengandung $62 \%$ cadangan karbon yang ditemukan di hutan primer.

Selain tanaman, juga ada ternak babi dan ternak sapi. Para petani menyadari bahwa limbah kulit kakao dapat dijadikan pakan ternak babi dan sapi dan bermanfaat secara ekonomis dan lingkungan, serta budaya local untuk pernikahan dan acara kematian. Sejalan dengan itu, Saputra (2012) melaporkan bahwa ternak sapi dan kambing yang diberikan pakan dari limbah kulit kakao menunjukkan pertumbuhannya cepat dan produktivitas susu meningkat dan berat badannya lebih meningkat dibandingkan jika hanya diberikan pakan yang standar seperti rerumputan, dedaunan, atau sayuran. 
Fatima: Analisis pendapatan usaha tani kakao

Tabel 2. Penggunaan Lahan untuk Usaha Produktif Non-Kakao

\begin{tabular}{clll}
\hline No. & \multicolumn{1}{c}{ Usaha produktif } & Total Produksi $(\mathbf{R p )})$ & \% \\
\hline 1 & Tanaman pangan & $12,380,000$ & 2.5 \\
2 & Tanaman perdagangan & $349,040,000$ & 69.2 \\
3 & Sayuran & $16,050,000$ & 3.2 \\
4 & Ternak & $98,800,000$ & 18.0 \\
5 & Tanaman kayu Jati, Mahoni & $36,000,000$ & 7,1 \\
\hline & Total Pendapatan & $504,200,000$ & 100 \\
\hline & Pendapatan/petani & $25,210,000$ & \\
& Total Pengeluaran & $65,700,000$ & \\
& Pengeluaran/petani & $3,285,000$ & \\
& Total Penjualan & $370,890,000$ & \\
& Penjualan/petani & $18,544,500$ & \\
\hline
\end{tabular}

Sumber: data primer (diolah), 2017

Tabel 2 menunjukkan tanaman perdagangan adalah produksi terbesar diikuti usaha ternak. Produksi tertinggi tanaman perdagangan adalah cengkeh, dan ternaknya adalah babi, dan sapi. Pendapatan tersebut, sebagian besar untuk konsumsi sendiri dan keperluan adat. Tanaman perdagangan hanya digunakan untuk investasi seperti biaya pembangunan rumah, beli kendaraan, dan lain-lain. Selengkapnya terlihat pada Tabel 3.

Tabel 3. Penggunaan Usaha Produktif untuk Konsumsi Sendiri, dan Lainnya

\begin{tabular}{llcccc}
\hline No. & \multicolumn{1}{c}{$\begin{array}{c}\text { Usaha } \\
\text { produktif }\end{array}$} & $\begin{array}{c}\text { Konsumsi } \\
\text { sendiri }\end{array}$ & $\%$ & $\begin{array}{c}\text { Lain-lain } \\
\text { ( Adat, social) }\end{array}$ & $\%$ \\
\hline 1. & Tanaman pangan & $7,880,000$ & 26.4 & 0 & 0 \\
2. & Sayuran & $1.020,000$ & 1.4 & 0 & 0 \\
3. & Ternak & $3,900,000$ & 13 & $35.800,000$ & 100 \\
4. & kayu Jati, Mahoni & $18,000.000$ & 60.2 & 0 & 0 \\
\hline & Total Pengeluaran & $12,800,000$ & 100 & $1,440,000$ & 100 \\
& Pengeluaran/petani & 640,000 & & 1.790 .000 & \\
\hline
\end{tabular}

Sumber: data primer (diolah), 2017

Table 3 terlihat bahwa semua usaha produktif dikonsumsi sendiri atau bersifat subsisten kecuali ternak sebagian besar untuk urusan adat dan tujuan sosial lainnya. Hal ini sejalan dengan pendapat Mubyarto (2016) pertanian yang subsisten adalah suatu sistem bertani yang tujuan utamanya untuk memenuhi keperluan hidup petani, dan keluarganya.

Data menunjukkan bahwa kakao dapat bertumbuh diantara tanaman produktif lainnya sebagai. sumber pendapatan. Sesuai pendapat Wahyudi (2013) bahwa pada habitat alaminya, tanaman kakao tumbuh di hutan tropis basah dan berkembang di bawah 
naungan tanaman hutan, dan kakao dan terlindung dari sebagian sinar adalah tanaman yang dapat ditanam matahari, seperti pada Tabel 4. dengan dicampur tanaman naungan lain

Tabel 4. Pendapatan Petani dari Usaha Produktif Non-kakao

\begin{tabular}{clcc}
\hline No. & Usaha produktif & Hasil Penjualan & \% \\
\hline 1 & Tanaman pangan & 4.500 .000 & 1.21 \\
2 & Tanaman perdagangan & 349.000 .000 & 94.1 \\
3 & Sayuran & 790.000 & 0.21 \\
4 & Ternak & 16.600 .000 & 4.48 \\
\hline & Total Pendapatan & 370.890 .000 & 100 \\
& Pendapatan/petani & 18.544 .500 & \\
\hline
\end{tabular}

Sumber: data primer (diolah), 2017

Usaha produktif yang dihasilkan sebagian besar dijual dan penghasilannya digunakan untuk kepentingan dalam keluarga termasuk pendidikan dan kesehatan.

\section{Analisis Usaha Tani Kakao}

Analisis Usaha Tani Kakao di Kabupaten Ende mengungkapkan hal-hal berikut.

\section{Aktivitas Petani Kakao}

Berdasarkan hasil penelitian, semua petani telah berpengalaman bertani kakao cukup lama yakni berkisar 6-10 tahun, dan sebanyak 69\% karena melanjutkan usaha orangtua. Pengembangan usaha kakao masih bersifat konvensional sehingga produksinya kurang maksimal. Namun atas inisiatif pemerintah maka sebagian besar petani sudah diperkenalkan dan menggunakan berbagai inovasi usaha kakao yang bernilai ekonomis diantaranya sudah kenal dengan P3S, penggunaan bibit dengan entris yang unggul.

Selanjutnya jarak tempuh dari rumah ke kebun kakao masih sebagian besar jauh dari jalan raya. Secara keseluruhan luas lahan untuk budidaya tanaman kakao seluas 64 ha dan setiap petani rata-rata 3 ha. Pada luasan lahan tersebut, terdapat 1.977 pohon kakao. Dari jumlah tersebut hanya 1.469 pohon yang sudah produktif dan memberikan hasil panen sebanyak $3.269 \mathrm{~kg}$ per panen/tahun, 210 pohon yang belum menghasilkan buah, dan 298 pohon yang rusak. Setiap petani memperoleh hasil rata-rata $163,45 \mathrm{~kg}$ dengan harga per $\mathrm{kg}$ Rp 28.000,-. Selengkapnya dapat dilihat pada table 05. Usaha pertanian kakao di kedua desa ini sudah dilaksanakan selama 22 tahun. Brambilla (2011) menyatakan petani yang menyediakan 
lahan yang luas untuk tanamannya maka produk petani akan secara signifikan meningkat dan produktivitas juga meningkat secara signifikan. Tabel 5 berikut memperlihatkan produksi kakao yang seharusnya berdasarkan teori dan fakta yang ada pada petani.

Tabel 5. Produksi Kakao Seharusnya dan Realitas pada Tingkat Petani

\begin{tabular}{|c|c|c|c|c|c|c|}
\hline \multirow[t]{2}{*}{$\overline{\text { No }}$} & \multirow{2}{*}{$\begin{array}{l}\text { Luas } \\
\text { (ha) }\end{array}$} & \multirow{2}{*}{$\begin{array}{l}\text { Jarak } \\
(\mathrm{m})\end{array}$} & \multirow{2}{*}{$\begin{array}{c}\text { Jumlah Tan. } \\
\text { (pohon) }\end{array}$} & \multirow{2}{*}{$\begin{array}{c}\text { Produksi/Th } \\
\text { (ton) }\end{array}$} & \multicolumn{2}{|r|}{ Harga } \\
\hline & & & & & Unit & Total \\
\hline \multirow[t]{2}{*}{1} & \multicolumn{6}{|c|}{ Menurut teori } \\
\hline & 1 ha & $3 \times 3$ & 1.111 & 2 ton $=2.000 \mathrm{~kg}$ & 28.000 & 56.000 .000 \\
\hline \multirow[t]{2}{*}{2} & \multicolumn{6}{|c|}{ Prediksi menurut teori dan fakta } \\
\hline & 64 ha & $3 \times 3$ & 71.104 & 128 ton $=128.000 \mathrm{~kg}$ & 28.000 & 3.584 .000 .000 \\
\hline 3 & \multicolumn{6}{|c|}{ Fakta di lapangan } \\
\hline 4 & \multicolumn{3}{|c|}{ Petani kehilangan keuntungan } & 124.731 & & 3.492 .468 .000 \\
\hline $\mathrm{Ke}$ & angan: & Seharusn & $\mathrm{R}: \mathrm{Re}$ & ada petani & & \\
\hline
\end{tabular}

Diadaptasi dari (Siswanto, 2012; Murtiningrum, 2016)

Salah satu faktor menurunnya produksi kakao adalah umur tanaman yg sudah tua yakni 20 tahun. Untuk itu diperlukan perawatan dengan P3S (pemupukkan, pemangkasan, dan sanitasi serta panen sering) dengan tujuan untuk meningkatkan produksi tanaman kakao. Ketika diperkenalkan P3S oleh LSM Tananua di Ende bekerjasama dengan Fakultas Pertanian Universitas Flores, dan pengalaman sebagai kader, maka $56 \%$ petani mulai melakukan perawatan kakao dengan P3S. Pengetahuan yang bermanfaat itu telah merubah sikap dan perilaku para petani kearah yang lebih baik. Selain itu, faktor yang mempengaruhi pengetahuan antara lain pendidikan, sosial budaya, ekonomi, lingkungan, pengalaman, dan usia. Sejalan dengan ini Sri (2011) menyatakan bahwa pengetahuan dipengaruhi oleh pengalaman, lama bertani dan lingkungan petani.

Aktivitas pendampingan dilakukan oleh LSM Tananua bersama dengan Fakultas Pertanian Universitas Flores, dan sebanyak $95 \%$ petani mendapatkan layanan di lokasi petani yang pelaksanaannya setiap dua bulan sekali dan layanan konsultasi secara insidentil. Untuk pelayanan di lapangan, petani diperkenalkan dan diajarkan cara menggunakan gunting pangkas dan memangkas, membuat rorak, dan untuk sanitasi dengan cara memetik semua buah kakao masak agar terbebas dari hama dan penyakit. 
Masa pemanenan dilakukan dalam dua musim yakni musim panen raya dilaksanakan pada bulan April sampai Juli, dan musim panen sepi pada bulan Juli sampai Maret. Waktu panen tergantung varietas kakao yang ditanam. Sebagian besar petani telah menggunakan parang untuk memanen dan mengupas kulit kakao. Hasil wawancara dengan seluruh petani bahwa kakao tidak langsung dikupas dan waktu pengupasan berbeda-beda. Sebanyak $77 \%$ setelah panen menyimpan selama 1-2 hari tergantung cuaca,dan sebanyak $23 \%$ menyimpan selama 1-2 minggu karena masih panen di kebun yang lain. Selanjutnya kakao dijemur dengan lama waktu penjemuran yang berbeda yakni sekitar 3-4 hari tergantung cuaca. Sebagian petani telah paham melakukan fermentasi sebelum menjemur dan ada sebagiannya tidak paham manfaat kakao difermentasi. Sesuai penelitian David (2018) bahwa lama fermentasi berpengaruh sangat nyata terhadap mutu biji kakao yang dihasilkan, dan waktu yang terbaik adalah enam hari. Mulato (2003) menyatakan waktu fermentasi adalah salah satu faktor penting penyebab meningkatnya kadar air sehingga dengan meningkatnya waktu fermentasi maka kadar air dalam biji kakao akan meningkat pula

Adopsi inovasi usaha kakao berdampak pada peningkatan produksi. Pengetahuan yang cukup akan memberikan alternatif terbaik bagi petani dalam memutuskan untuk mengadopsi suatu inovasi. Hal ini sesuai pendapat Welson (2011) yang menyatakan bahwa pengetahuan menjadi dasar sebuah adopsi dapat dilakukan dengan baik atau tidak. Sormin (2012) juga menyatakan bahwa pengetahuan merupakan salah satu komponen perilaku petani yang turut menjadi faktor dalam adopsi inovasi.

Tenaga kerja diperlukan untuk menyelesaikan pekerjaan mulai dari persiapan lahan, bibit, benih, perawatan dengan pemupukan, membuat rorak, pemangkasan,dan sanitasi panen, pengelolaan pasca panen, dan penjualan. Rata-rata tenaga kerja diperlukan 4 orang yang bersumber dari tenaga kerja dalam rumah. Tenaga untuk menjual ke pasar adalah para perempuan karena sekalian berbelanja. Petani juga menyewa dan gotong royong jika kekurangan tenaga. Suryana (2000) mengatakan bahwa penduduk dapat berperan sebagai sumber tenaga kerja, tenaga ahli, pimpinan perusahaan, dan 
tenaga usahawan yang diperlukan untuk memimpin dan menciptakan kegiatan pembangunan ekonomi.

\section{Analisa Keuntungan dan Kelayakan}

\section{Usaha Tani Kakao}

Berdasarkan hasil penelitian dan melalui wawancara dengan petani ditemukan bahwa para petani tidak pernah melakukan analisis dalam usaha tani, karena mereka tidak tahu.

\section{Pemasaran}

Aktivitas pemasaran mencakup produk, harga, promosi, lokasi penjualan.Penjualan dilakukan oleh petani dengan mempertimbangkan beberapa hal berikut.(1) menetapkan pembeli: petani menjual kepada pedagang antar pulau karena pertimbangan harga yang lebih baik dan pedagang kecamatan dan kabupaten; (2)menetapkan pemasaran yang mencakup bentuk produk yang dijual semuanya biji kering dengan mutu asalan, dan metode penjualan langsung ke pembeli, dengan metode pembayaran tunai; (3) menetapkan packing. Untuk menjaga mutu yang baik, biji kakao yang kering dikemas dalam karung berpori agar tidak lembab; (4) waktu, mengingat petani tidak memiliki gudang khusus yang memadai, sebagian besar petani menyimpan dalam kurun waktu 1-4 minggu sebelum dijual; .(5) transportasi: jenis transportasi penjualan yang digunakan semuanya menggunakan kendaraan.; (6) minat pembeli: kakao yang dihasilkan sangat diminati dan semua kakao terjual; (7) konsep harga dan mutu: semua petani berorientasi kualitas produk yang baik pasti berdampak pada harga yang baik; (8) sumber informasi; diperoleh dari para pembeli dan sesama petani; dan (9) strategi penjualan: sebagian besar langsung setelah panen dan menjual pada saat harga baik.

Aktivitas penjualan yang dilakukan oleh para petani tersebut merupakan praktek pemasaran yang berusaha menghasilkan produk yang berkuaitas untuk memenuhi kebutuhan pasar. Hal ini sejalan dengan pendapat Kotler (2014) bahwa pemasaran suatu proses sosial dan manajerial yang didalam individu dan kelompok mendapatkan apa yang mereka butuhkan dan inginkan dengan menciptakan, menawarkan, dan mempertukarkan produk yang bernilai dengan pihak lain.Konsep pemasaran kakao yang dilakukan di Desa Kedebodu dan Rewaranga, telah mendekati konsep teori pemasaran. 
Permasalahan, Solusi, dan Strategi Usaha Tani Kakao

\section{PermasalahanUsaha Tani Kakao}

Realitas menunjukkan bahwa usaha tanaman kakaopasti melewati berbagai
masalah.Permasalahan tersebutdianalisis berdasarkan fase pengembangan tanaman kakao yang dilakukan petani. Lebih jelas dapat dipaparkan pada Table 6 berikut.

Tabel 6. Permasalahan petani kakao di Kabupaten Ende

\begin{tabular}{|c|c|c|c|c|c|c|}
\hline Permasalahan & \multicolumn{6}{|c|}{ Persentasi Jawaban Terhadap Permasalahan } \\
\hline 1. Persiapan lahan & 62 & $\%$ & $\begin{array}{l}\text { Tenaga kerja } \\
\text { kurang }\end{array}$ & 38 & $\%$ & $\begin{array}{l}\text { Peralatan } \\
\text { kurang }\end{array}$ \\
\hline 2. Bahan Tanam & 100 & $\%$ & Tak ada klon baru & - & & $\begin{array}{l}\text { Tanaman } \\
\text { mati }\end{array}$ \\
\hline 3. Pemupukan & 98 & $\%$ & Tak ada pupuk & - & & \\
\hline 4. Hama/Penyakit & 77 & $\%$ & Tidak tahu atasi & 23 & $\%$ & $\begin{array}{l}\text { biji kakao } \\
\text { hitam }\end{array}$ \\
\hline $\begin{array}{l}\text { 5. Panen \& pasca } \\
\text { panen }\end{array}$ & 62 & $\%$ & $\begin{array}{l}\text { Tenaga kerja } \\
\text { kurang }\end{array}$ & 38 & $\%$ & TK cukup \\
\hline 6. Pemasaran & 54 & $\%$ & harga berfluktuasi & 46 & $\%$ & $\begin{array}{l}\text { Kurang info } \\
\text { pasar }\end{array}$ \\
\hline $\begin{array}{c}\text { Solusi } \\
\text { Fase: }\end{array}$ & \multicolumn{6}{|c|}{ Persentasi Jawaban Terhadap Solusi } \\
\hline 1. Persiapan lahan & 62 & $\%$ & sewa tenaga & 38 & $\%$ & Pinjam \\
\hline 2. Pemupukan & 92 & $\%$ & tak ada solusi & 8 & $\%$ & Rorak \\
\hline 3. Bahan Tanam & 100 & $\%$ & tidak tahu & 0 & $\%$ & - \\
\hline 4. Hama/Penyakit & 77 & $\%$ & tidak tahu & 23 & $\%$ & P3S \\
\hline $\begin{array}{l}\text { 5. Panen dan pasca } \\
\text { panen }\end{array}$ & 62 & $\%$ & sewa tenaga & 38 & $\%$ & $\begin{array}{l}\text { Gotong } \\
\text { royong }\end{array}$ \\
\hline 6. Pemasaran & 54 & $\%$ & Jual & 46 & $\%$ & tanya teman \\
\hline
\end{tabular}

Sumber :dataprimer(diolah),2017

Tabel 6 memperlihatkan permasalahan ditinjau dari enam fase yakni fase persiapan lahan, panen, dan pasca panen, sebanyak $62 \%$ menyatakan tenaga kerja kurang solusinya dengan sewa, gotong royong, dan sebanyak $38 \%$ peralatan kurang dan mengatasinya dengan meminjam pada sesama petani. Bahan tanam 100\% menyatakan tidak ada klon baru dan belum tahu mengatasinya. Pemeliharan $92 \%$ petani tidak melakukan pemupukan karena belum memiliki pengetahuan tentang pemupukan kakao dan $8 \%$ petani sudah mengerti dengan membuat rorak. Masalah hama dan penyakit, $77 \%$ petani tidak tahu mengatasinya dan $23 \%$ masalah biji kakao berwarna hitam dan solusinya P3S. Masalah yang berkaitan dengan pemasaran adalah $54 \%$ petani 
Fatima: Analisis pendapatan usaha tani kakao

menyatakan harga berfluktuasi dan

pengetahuan dalam pemumpukkan solusinya dengan menjual di pasar, berdampak pada rendahnya produksi. sedangkan masalah lain adalah kendala dengan kendaraan dan kurangnya info pasar sebanyak $46 \%$, solusinya adalah dengan menyewa kendaraan dan bertanya pada teman.

Hasil penelitian pada Tabel 6 menunjukkan bahwa pada fase pemupukkan $92 \%$ petani tidak melakukan pemupukan. Kurangnya Lihat tabel 5. Sejalan dengan pendapat Karmawati (2010) bahwa pemupukan dan pengolahan tanah bertujuan untuk meningkatkan dan mempertahankan produktivitas tanaman yang menguntungkan secara berkesinambungan. Tabel 7 berikut adalah strategi pengembangan yang telah dilakukan.

Tabel 7. Strategi Pengembangan Petani Kakao di Kabupaten Ende

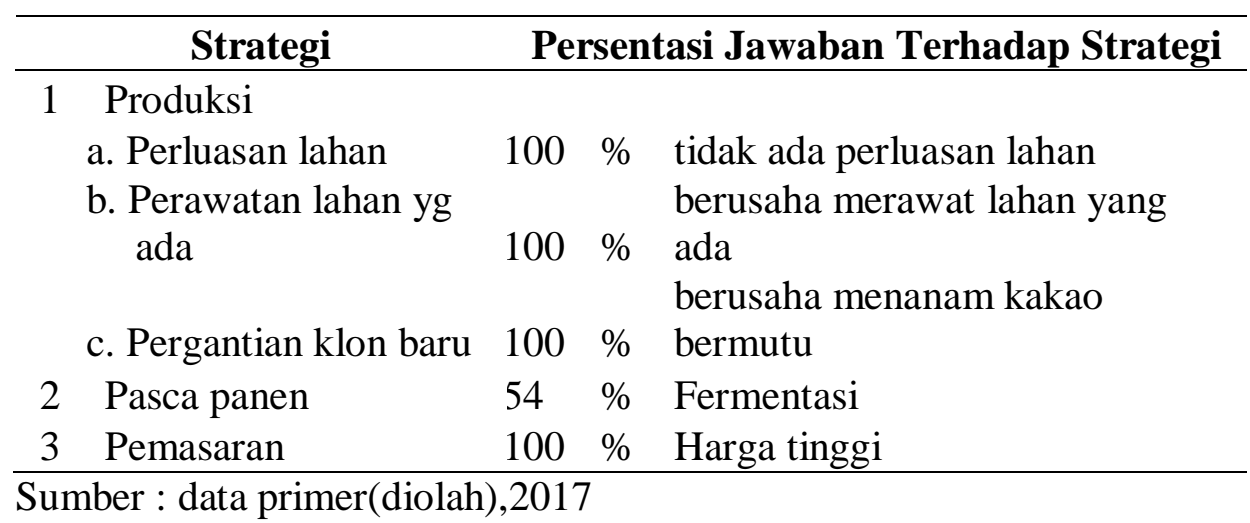

Tabel 7 memperlihatkan bahwa strategi $100 \%$ petani tidak melakukan perluasan lahan dan untuk meningkatkan produksi dilakukan intensifikasi dengan merawat lahan yang ada secara lebih baik. Untuk itu pada saat pasca panen mereka melakukan fermentasi sebesar $54 \%$ dan pemeliharaan dengan melakukan P3S $46 \%$. Kondisi ini sejalan dengan pendapat Slameto (2014) dan Firmana (2016) bahwa penerapan metode ini lebih efektif bagi para petani yang pendidikan masih rendah sehingga para petani lebih ahli dalam manajemen kebun kakao. Selanjutnya dilakukan analisis keuntungan dan kelayakan yang diperoleh Para Petani dari usaha tani kakao. Selengkapnya tertera pada Tabel 8 dan Tabel 9. 
Tabel 8. Analisis Keuntungan Usaha Tani Kakao

\begin{tabular}{|c|c|c|c|c|c|}
\hline No & Komponen & Vol & Satuan & $\begin{array}{l}\text { Harga/unit } \\
(\mathbf{R p})\end{array}$ & Jumlah (Rp) \\
\hline $\mathbf{A}$ & BIAYA & & & & \\
\hline \multirow[t]{5}{*}{ I } & Perawatan kebun & & & & \\
\hline & 1. Tenaga kerja sewaan & 7 & $\mathrm{HOK}$ & 55000 & 385,000 \\
\hline & 2. Tenaga kerja sendiri dalam RT & 25 & $\mathrm{HOK}$ & 55000 & $1,375,000$ \\
\hline & 3. Aplikasi Teknologi P3S & 14 & $\mathrm{HOK}$ & 55000 & 770,000 \\
\hline & Sub Total & & & & $2,530,000$ \\
\hline \multirow[t]{4}{*}{ II } & Biaya Panen & & & & \\
\hline & 1. Tenaga kerja sewaan & 2 & $\mathrm{HOK}$ & 55.000 & 110.000 \\
\hline & $\begin{array}{l}\text { 2. Tenaga kerja sendiri dalam } \\
\text { RT }\end{array}$ & 25 & HOK & 55.000 & $1,375,000$ \\
\hline & Sub Total & & & & $1,485,000$ \\
\hline \multirow[t]{12}{*}{ III } & Biaya Olah Biji Kering Asalan & & & & \\
\hline & Tenaga Sortasi dan Penjemuran & 25 & $\mathrm{HOK}$ & 55,000 & $1,375,000$ \\
\hline & Peralatan & 25 & parang & 55,000 & $1,375,000$ \\
\hline & & 25 & pacul & 55,000 & $1,375,000$ \\
\hline & Sub Total & & & & $4,125,000$ \\
\hline & Biaya Olah Biji Kering Fermentas & & & & \\
\hline & $\begin{array}{l}\text { 1. Tenaga pembelahan dan } \\
\text { sortasi }\end{array}$ & 25 & HOK & 55.000 & $1,375,000$ \\
\hline & 2. Tenaga pengangkutan & 20 & $\mathrm{HOK}$ & 55,000 & $1,100,000$ \\
\hline & 3. Tenaga pembersihan & 25 & $\mathrm{HOK}$ & 55,000 & $1,375,000$ \\
\hline & 4. Tenaga pengeringan/jemur & 25 & $\mathrm{HOK}$ & 55,000 & $1,375,000$ \\
\hline & 5. Peralatan pengeringan/terpal & 20 & BUAH & 150.000 & $3,000,000$ \\
\hline & Sub Total & & & & $8,225,000$ \\
\hline \multirow[t]{5}{*}{ IV } & Biaya penjualan & & & & \\
\hline & 1. Transportasi penjualan & 20 & kali & 25,000 & 500,000 \\
\hline & 2. Tenaga kerja penjualan & 14 & HOK & 55,000 & 770,000 \\
\hline & Sub Total & & & & $1,270,000$ \\
\hline & TOTAL BIAYA & & & & $\mathbf{1 7 , 6 3 5 , 0 0 0}$ \\
\hline \multirow[t]{3}{*}{$\mathbf{B}$} & PENDAPATAN & & & & \\
\hline & $\begin{array}{l}\text { Produksi \& penjualan biji kering } \\
\text { asalan }(\mathrm{kg})\end{array}$ & 3269 & $\mathrm{Kg}$ & 28,000 & $91,532,000$ \\
\hline & PENDAPATAN & & & & $91,532,000$ \\
\hline $\mathbf{C}$ & KEUNTUNGAN & & & 73,897,000 & $\begin{array}{l}\text { B/C Ratio : } \\
5,24 \%\end{array}$ \\
\hline
\end{tabular}

Sumber :dataprimerdiolah,2017 
Fatima: Analisis pendapatan usaha tani kakao

Tabel 9. Analisis Kelayakan Usaha Tani Kakao

\begin{tabular}{llcl}
\hline \multicolumn{4}{c}{ ANALISIS USAHA TANI KAKAO } \\
\hline No & Komponen Biaya & Jumlah $(\mathbf{R p})$ & Keterangan \\
\hline A & & & \\
I & Perawatan kebun & $2,530,000$ & \\
II & Biaya Panen & $1,485,000$ & \\
III & Biaya Olah Biji Kering Asalan & $4,125,000$ & \\
IV & Biaya Olah Biji Kering Fermentasi & $8,225,000$ & \\
IV & Biaya penjualan & $1,095,000$ & \\
Total Biaya & $\mathbf{1 7 , 4 6 0 , 0 0 0}$ & Total Biaya \\
& & $\mathbf{8 7 3 , 0 0 0}$ & Biaya/ Orang \\
\hline B & PENDAPATAN & $\mathbf{9 1 , 5 3 2 , 0 0 0}$ & Total \\
& & $\mathbf{4 , 5 7 6 , 0 0 0}$ & Pendapatan \\
& & & Pendapatan/ \\
& & 5,24 &
\end{tabular}

Sumber :dataprimerdiolah,2017

Berdasarkan analisis usaha

musim panen dan per petani memperoleh ekonomi rumah tangga petani kakao, penerimaan sebesar Rp 4.576.600,-.

Pendapatan usahatani kakao yaitu biaya yang paling banyak dikeluarkan adalah pengeluaran rutin rumah tangga, dan kedua urusan sosial dan pembangunan. Urusan sosial yang dimaksudkan adalah sumbangan untuk urusan adat Ende-Lio yang disebut dengan "wurumana".

\section{SIMPULAN}

Total biaya usahatani kakao di Kecamatan Ende Timur sebesar Rp 17.635.000,- dan perpetani Rp. $881,750,-\quad$ per musim panen. Hasil produksi rata - rata per musim panen dari usahatani kakao adalah $3.269 \mathrm{~kg}$ dengan harga jualRp. 28.000 per/kg maka total penerimaan dari usahatani kakao adalah Rp. 91.532.000,- per penerimaan Rp. 91.532.000,- per musim panen dikurangi biaya total Rp. 17,635,000 per musim panen sehingga diperoleh pendapatan sebesar Rp 73,897,000,- atau per petani memperoleh Rp 3.694.850,- per musim panen (satu tahun). Pendapatan di luar kakao sebesar Rp 224,200,000 - biaya Rp 194,267,000 maka pendapatannya Rp 29,933,000 atau RP 1,496,650/petani.

$\mathrm{B} / \mathrm{C}$ ratio sebesar $5,24 \%$ yang berarti usaha kakao menguntungkan dan layak untuk dikembangkan. Faktor yang mempengaruhi usaha kakao di kecamatan Ende Timur Kabupaten Ende antara lain, factor internal petani mencakup tingkat pendidikan, partisipasi 
gender, usia tenaga kerja, dan faktor eksternal kurangnya partisipasi pemerintah, lembaga pendidikan, umur tanaman kakao yang sudah tua, dan ketersediaan teknologi P3S, fermentasi, penjemuran, dan penyimpanan.

\section{UCAPAN TERIMA KASIH}

Disampaikan terimakasih kepada semua para petani yang telah berkenan untuk memberikan infomasi tentang usaha kakao dan segala problemanya, kepada semua pihak yang telah berpartisipasi untuk mendampingi para petani selama 8 bulan, semua mahasiswa, dan tim dari Fakultas Pertanian yang telah berpartisipasi dalam kegiatan, serta semua pihak yang terlibat untuk meningkatkan pendapatan para petani kakao di Kecamatan Ende Selatan.

\section{DAFTAR PUSTAKA}

Amini. 2013. Analisis Partisipasi Wanita Nelayan dalam Program Usaha Garam Rakyat. Media Ilmiah, 3841.

BPTP (Balai Penelitian Tanaman Pangan). 2011. Pembinaan Kelompok Tani dalam Pengembangan Kelembagaan Tani. Jakarta: Litbang Deptan.

Brambilla,I., Guido G. P. 2011. Market Structure, Outgower Contracts And Farm Output. Evidence From Cotton Reforms In Zambia.
Oxford Economic Papers. 63(4). Pp: 740-766.

David, J. 2018. Perbaikan Mutu Biji Kakao Dengan Perlakuan Suhu. Seminar Nasional Agroinovasi Spesifik Lokasi Untuk Ketahanan Pangan Pada Era Masyarakat Ekonomi ASEAN (pp. 16711678). Bogor: Pusat Perpustakaan dan Penyebaran Teknologi Pertanian.

Firmana, F. 2016. Dampak Penerapan Program SLPTT terhadap Pendapatan Usahatani Padi diKecamatan Telagasari Kabupaten Karawang. Jurnal Agrikultura. https://doi.org/10.24198/agrikultur a.v27i1.8475, 50-56.

Gay,L.R. dan Dielh,P.L, .1992. Research Methods for Businessand Management. New York :Macmillan Publishing Company

Gustiyana, H. 2003. Analisis Pendapatan Usahatani untuk Produk Pertanian. Jakarta: Salemba.

Hadiana. 2013. Usahatani Mangga Gedong Gincu Berdasarkan Status Penguasaan Lahan. Majalengka Jawa Barat: LPPM Universitas Majalengka.

Hariadi. 2011. Dinamika Kelompok. Bandung: CV. Manda Maju.

Hermanto, B. A. 2015. Analisis Laporan Keuangan . Jakarta: Lentera Ilmu Cendekia.

Ikbal, M. 2014. "Peranan Kelompok Tani Dalam Meningkatkan Pendapatan Petani Padi Sawah Di Desa Margamulya Kecamatan Bungku Barat Kabupaten 
Morowali". Jurnal Agrotekbis, Vol. 2 No. 5 (Oktober 2014), h. 506.

Jaweng, R. R. (2015). Upaya Peningkatan Pendapatan Petani Kakao di Kabupaten Ende . Ende, Nusa Tenggara Timur, Indonesia. Retrieved from https://media.neliti.com/media/pub lications/324-ID-upayapeningkatan-pendapatan-petanikakao-di-kabupaten-ende-ntt.pdf.

Karmawati, E. M. 2010. Budidaya dan Pascapanen Kakao. Bandung: Pusat Penelitian dan Pengembangan Perkebunan.

Kotler, P. 2014. Dasar-Dasar Pemasaran, Edisi ke-19. Jakarta: PT. Indeks.

Kotto,S. J., Woomer, P. L., Appolinaire, M., Louis, Z. (1997). Carbon dynamics in slash-and-bum agriculture and land use alternatives of the humid forest zone in Cameroon. In Agriculture, Ecosystems and Environment Volume 65, 245-256.

Kusnadi. 2005. Kepemimpinan Kontaktani dalam Meningkatkan Efektifitas Kelompok Tani. Bogor: IPB.

Mubyarto. 2016. Pengantar Ekonomi Pertanian. Jakarta: LP3ES.

Mulato, S. dan S. Widyotomo. 2003. Teknik Budidaya dan Pengolahan Hasil Tanaman Kakao.Pusat Penelitian Kopi dan Kakao Indonesia.Jember.

Murtiningrum, M., dan Bantacut, T. 2016. Review: Potensidan Arah Pengembangan Agroindustri Berbasis Kakao diProvinsi
PapuaBarat. Agrointek,10(1), 1. https://doi.org/10.21107/agrointek. v10i1. 2020

Saputra, T.H. 2012. Potensi limbah kulit kakao untuk pakan ternak di Kecamatan Gedong Tataan. Retrieved from https://triharyantosaputra.wordpres s.com.

Siswanto. 2012. Pengendalian-HamaUtama-Kakao. Retrieved 2019, from

http://perkebunan.litbangpertanian. go.id/dbasebun/asset_dbasebun/Pe nerbitan-20141207121322-pdf.

Slameto. 2014. Efektivitas Proses Pembelajaran Sekolah Lapang Oleh Komunitas Petani Di Lampung. Jurnal Agro Ekonomi, 35-55.

Soekartawi. 2005. Analisis Usaha Tani. Jakarta: Universitas Indonesia Press.

Soeratno. Linconl, A. 2005. Metodologi Penelitian untuk Ekonomi dan Bisnis. Yogyakarta: UPP AMP YKPN.

Sormin, E. 2012. Analisis Tingkat Pengetahuan Petani Terhadap Manfaat Lahan Padi Sawah di Kab. Sedang Bedagai. Journal Social Economic of Agricultural and Agribusiness, 1-14.

Sri, S. M. R., dan B. Honorita. 2011. Perilaku petani dalam usahatani di lahan rawa lebak. Prosiding Seminar Nasional Budidaya Pertanian : (pp.115-128

Suryana. 2000. Ekonomi Pembangunan Problematika dan Pendekatan. Jakarta: Salemba Empat. 
Terhorst, H. 2014. Sustainable Cocoa Production in Agroforestry Systems: Linked to Low Carbon Emission Economic Development [materi presentasi]. Jakarta: GIZ Forests and Climate Chane Programme.

Wahyudi. (2013). Pengaruh Kerapatan Pohon Penaung Terhadap Daya Hasil Kakao. Pelita Perkebunan, 68-73.

Wahyuni, S. Hutubessy, J.I.B., Witi, F.L. (2019). Peningkatan Produksi Kakao melalui Penerapan Teknologi Kakao Sehat pada Kelompok Tani "Wonga Mengi" di Desa Kedebodu, Kecamatan Ende Selatan, Kabupaten Ende, Propinsi Nusa Tenggara Timur.
PRIMA Journal of Community Empowering and Services. 3(2), 56-62, 2019, 56-62.

Welson, M.W., B.O.L. Suzana dan H.A. Siagian. 2011. Penerapan teknologi usahatani padi sawah.ASE. 7(1) : 53-57

Wibowo. 2006. Faktor karakteristik peternak yang mempengaruhi sikap terhadap program kredit sapi potong di kelompok ternak Andiniharjo Kab.Sleman Yogyakarta. Media Peternakan, 176-186.

Widodo. 2012. Peran perempuan dalam sistem nafkah rumah tangga nelayan. Ekonomi Pembangunan, $1-7$. 